\title{
ANALISIS KONTRIBUSI PAJAK KENDARAAN BERMOTOR TERHADAP PENDAPATAN ASLI DAERAH PROVINSI SULAWESI UTARA PERIODE (2013-2017)
}

\author{
Pinkan Grace Assa ${ }^{1}$, Hendrik Manossoh ${ }^{2}$, Lidia Mawikere ${ }^{3}$ \\ 1,2,3 Jurusan Akuntansi, Fakultas Ekonomi dan Bisnis, Universitas Sam Ratulangi, Jl. Kampus Bahu, Manado \\ 95115, Indonesia \\ Email : pinkgrace.assa@gmail.com
}

\begin{abstract}
Regional Tax is one component of Regional Original Income which has very good prospects to be developed. Motor vehicle tax is one source of income in the Province. Regional Vehicle Revenue Tax North Sulawesi Province (2013-2017) The method of analysis in this study is a qualitative descriptive analysis method, namely tax revenues, especially motor vehicles in the period (2013-2017) using the contribution ratio. The results of the study explain the small contribution given by motor vehicle tax, and there are still many people who have not been obedient in paying taxes.
\end{abstract}

Keywords: Regional Tax, Motor Vehicle Tax, Contributions, Receipts, Regional Income

\section{PENDAHULUAN}

Pajak daerah menjadi salah satu komponen PAD yang baik untuk ditingkatkan. Pajak kedaraan bermotor (PKB) menjadi sumber dari penerimaan daerah Provinsi Sulawesi Utara. Pajak kendaraan bermotor menjadi hal yang menarik untuk diteliti. Provinsi Sulawesi Utara merupakan daerah yang sedang melakukan pembangunan dan daerah yang sedang mengalami perkembangan. Di Provinsi Sulawesi Utara penerimaan pajak kendaraan bermotor masih mengalami kendala, masih ditemukan pengguna kendaraan bermotor yang belum memenuhi kewajiban membayar pajak kendaraan bermotor. Berdasarkan uraian inilah maka perlu dilakukan Analisis dalam penelitian Pajak Kendaraan bermotor. Berdasarkan latar belakang permasalahan sehingga dapat di rumuskan permasalahan didalam penelitian ini ialah Bagaimana Kontribusi PKB Terhadap PAD Provinsi Sulut? bertujuan untuk melihat Berapa Besar Kontribusi PKB Terhadap PAD Provinsi Sulut dalam kurun waktu 5tahun yaitu pada Periode (2013-2017).

\section{TINJAUAN PUSTAKA}

Pengertian Akuntansi. Akuntansi menyediakan informasi terhadap pihak-pihak berkepentingan dengan situasi dan aktivitas ekonomi dalam suatu instansi Warren (2017: 6). Ada 3 aktivitas dasar dari akuntansi, yaitu mencatat, mengkomunikasikan serta mengidentifikasi kejadian ekonomi dari perusahaan tersebut Weygant $(2015: 4)$

Akuntansi Pajak. Dalam Agoes dan Estralita (2013:10) Akuntansi pajak adalah menetapkan besarnya pajak terutang berdasarkan laporan keuangan yang disusun oleh perusahaan.

Akuntansi Sektor Publik. Mahmudi (2011 : 22) menyatakan akuntansi sektor publik berperan penting di dalam suatu negara untuk efektivitas pengelolaan keuangan daerah, pemeriksaan keuangan, pelaporan keuangan dan perwujudan tata kelola pemerintahan yang baik.

Pajak Daerah. Dalam Siahaan (2013: 9) Pajak Daerah ialah pembayaran dari daerah terhadap orang pribadi atau badan tanpa imbalan yang seimbang namun wajib, oleh karena itu pajak daerah dapat di paksakan untuk pengguna pajak berdasarkan UU. 
Pajak Kendaraan Bermotor. Dalam Undang - undang No. 28 tahun 2009 tentang Pajak Daerah dan Retribusi Daerah, Pajak Kendaraan Bermotor adalah pajak atas kepemilikan dan/atau penguasaan kendaraan bermotor. Objek Pajak Kendaraan Bermotor, yang menjadi objek Pajak Kendaraan Bermotor adalah kepemilikan dan/atau penguasaan kendaraan bermotor. Dikecualikan sebagai objek pajak PKB adalah kepemilikan dan/atau penguasaan kendaraan bermotor oleh.

1. Kereta api; Kendaraan Bermotor yang semata-semata digunakan untuk keperluan pertahanan dan keamanan Negara;

2. Kendaraan Bermotor yang dimiliki dan/atau dikuasai kedutaan, konsultan, perwakilan Negara asing dengan asa timbal balik dan lembaga-lembaga internasional yang memperoleh fasilitas pembebasan pajak dari Pemerintah; dan

3. Objek Pajak lainnya yang ditetapkan dalam Peraturan Daerah. Subjek Pajak Kendaraan Bermotor, Menurut pasal 4 Undang-undang Nomor 28 Tahun 2009 Tentang Pajak Daerah dan Retribusi Daerah, yang menjadi subjek Pajak Kendaraan Bermotor adalah Orang Pribadi atau Badan yang memiliki dan/atau menguasai kendaraan bermotor.

Pendapatan Asli Daerah. Menurut Siregar (2015:31) PAD menjadi sumber penerimaan yang diperoleh Daerah dari sumber-sumber di wilayahnya sendiri yang diambil berdasarkan Peraturan Daerah.

Penelitian Terdahulu. Ratu Inggrini, Jenny Morasa, Lidia Mawikere (2018). Analisis penerimaan Pajak Bea Balik Nama Kendaraan Bermotor di Sulawesi Utara. Hasil penelitian diketahui mengalami penurunan. Wahidah (2018)). Analisis kontribusi (PKB) Terhadap (PAD) di Kota Palopo. Kontribusi pajak kendaraan bermotor terhadap PAD di Kota Palopo periode 2012-2015 adalah sangat baik, dengan nilai rata-rata adalah sebesar 55,20\%.

\section{METODE PENELITIAN}

Jenis Penelitian. Jenis Penelitian ini ialah Kualitatif Deskripstif di lakukan di BP2RD dengan jangka waktu dari Bulan Mei dan di akhiri di bulan Agustus.

Jenis, Sumber dan Metode Pengumpulan Data. Kuncoro (2011 : 145) Jenis data menggunakan data kualitatif dan kuantitatif. Data kualitatif yang di sajikan secara kalimat, data kuantitatif yang menggunakan angka. Sumber data yang digunakan ialah data primer yang diperoleh dari BP2RD Provinsi Sulawesi Utara. Supardi (2013:16) mengatakan ada dua sumber pengumpulan data yang di gunakan ialah sumber primer dan sekunder, dimana: (1) Sumber primer, data yang didapat atau dikumpulkan langsung, sedangkan (2) sumber sekunder ialah tidak langsung bertatap muka kepada pihak pengumpul data.

Teknik dalam pengumpulan data pada penelitian adalah: (1) wawancara; (2) dokumentasi. Menurut Sujarweni (2014:31), wawancara yaitu kegiatan memperoleh informasi secara jelas. Dokumentasi, yaitu mengumpulkan dokumen-dokumen yang berhubungan dalam penelitian untuk mengumpulkan data-data lainnya yang diperlukan.

Teknik Analisis. Analisis data yang digunakan ialah perhitungan Presentase Realisasi Penerimaan (PKB) dibandingkan dengan Realisasi Penerimaan (PAD) dikalikan 100\% (Handoko 2013 : 03).

\section{HASIL PENELITIAN DAN PEMBAHASAN \\ 4.1. Hasil Penelitian}

Dari hasil yang diterima, Nilai Selisih target dan realisasi PKB periode 2013-2017 menunjukan angka yang relatif rendah dan berpengaruh pada PAD. 


\subsection{Pembahasan}

Tabel 1. Anggaran/Target dan Realisasi PAD Tahun 2013-2017

\begin{tabular}{ccrrr}
\hline No & Periode & \multicolumn{1}{c}{ Target (Rp.) } & \multicolumn{1}{c}{ Realisasi (Rp.) } & \multicolumn{1}{c}{$\%$} \\
\hline 1 & 2013 & $764,063,464,750$ & $785,467,967,366$ & 102.8 \\
2 & 2014 & $991,101,010,028$ & $938,596,052,854$ & 94.702 \\
3 & 2015 & $1,089,288,358,000$ & $1,012,945,961,386$ & 92.992 \\
4 & 2016 & $979,353,945,492$ & $1,123,743,474,436$ & 114.74 \\
5 & 2017 & $1,076,342,496,000$ & $939,060,341,245$ & 87.245 \\
\hline
\end{tabular}

Sumber Data : BP2RD Provinsi Sulawesi Utara, 2018

Dapat dilihat dari setiap tahun penerimaan Pajak kendaraan Bermotor belum mencapai Target sehingga sangat berpengaruh dalam kontribusi PAD.

Tabel 2. Kontribusi PKB Terhadap Pendapatan Asli Daerah Provinsi Sulawesi Utara Peiode 2013-2017

\begin{tabular}{|c|c|c|c|}
\hline Periode & $\begin{array}{l}\text { Pajak Kendaraan Bermotor } \\
(\text { Rp) }\end{array}$ & $\begin{array}{c}\text { Pendapatan Asli Derah } \\
(\mathbf{R p})\end{array}$ & $\begin{array}{c}\text { Kontribusi } \\
(\%)\end{array}$ \\
\hline 2013 & $\operatorname{Rp} 209,315,814,738$ & Rp 667,486,863,891 & 31.36 \\
\hline 2014 & $\operatorname{Rp} 234,640,571,263$ & $\operatorname{Rp} 785,206,204,619$ & 29.88 \\
\hline 2015 & Rp 260,975,957,735 & Rp 837,020,757,499 & 31.18 \\
\hline 2016 & Rp 276,185,514,989 & Rp 838,345,626,536 & 32.94 \\
\hline 2017 & Rp 266,918,788,764 & Rp $802,455,358,383$ & 33.26 \\
\hline
\end{tabular}

Sumber: Data Olahan 2018

Pada Tabel 4.10 Realisasi Pajak Kendaraan Bermotor mengalami fluktuatif sehingga kontribusi terhadap PAD sangat kecil atau tidak mencapai target.

\section{KESIMPULAN DAN SARAN}

\subsection{Kesimpulan}

Kesimpulan atas penelitian ini adalah bahwa kontribusi pajak kendaraan bermotor dalam kurun waktu 2013-2017 mengalami fluktuatif.

\subsection{Saran}

Pengawasan pemerintah terhadap instansi terkait lebih ditingkatkan guna untuk memberikan kontribusi untuk Pendapatan Asli Daerah di Provinsi Sulawesi Utara di tahuntahun selanjutnya.

\section{DAFTAR PUSTAKA}

Agoes, Sukrisno dan Estralita Trisnawati. 2013. Akuntansi Perpajakan Edisi 3. SalembaEmpat. Jakarta

Handoko P, Sri. 2013. Analisis Tingkat Efektivitas Pajak Daerah Sebagai Sumber PendapatanAsli Daerah Kota Pontianak. diakses pada Tanggal 7 November 2015 dari http://jurnal.untan.ac.id/index.php/JEDA2/article/view/1361

Kuncoro, M. (2011) Metode Riset Untuk Bisnis dan Ekonomi Bagaimana Meneliti dan Menulis Tesis?. Edisi 3, Jakarta: Erlangga

Mahmudi. 2011. Akuntansi Sektor Publik. Andi. Yogyakarta.

Ratu Inggrini1, Jenny Morasa2, Lidia Mawikere3. 2018. Analisis Penerimaan PajakBea Balik Nama Kendaraan Bermotor di Sulawesi Utara. Jurnal Riset Akuntansi Going Concern 13(3), 2018, 303-310. 
Siahaan, P Marihot. 2013. Pajak Daerah \& Retribusi Daerahedisi 2. Raja GrafindoPersada.Jakarta

Siregar, Baldric. 2015. Akuntansi Sektor Publik. UPP-STIM YKPN. Yogyakarta.

Sujarweni, 2014. Metodologi Penelitian Lengkap, Praktis dan MudahDipahamiEdisi 1. Penerbit Index. Yogyakarta.

Supardi. 2013. Aplikasi Statistika dalam Penelitian. Jakarta : Prima Ufuk Semesta

Undang-Undang Nomor 28 Tahun 2009. Tentang pajak daerah dan retribusidaerah. Jakarta

Wahidah.2018. Analisis Kontribusi Pajak Kendaraan Bermotor (PKB) TerhadapPendapatan Asli Daerah (PAD) Di Kota Palopo.Journal of Economic, Managementand Accouunting.. Faculty of Economic Andi Djemma University of Palopo.

Warren, Carl S., James M. Reeve, and Jonathan Duchac. Financial Accounting. 15thed. USA: Cengage Learning, 2017.

Weygant, Jerry J., Paul D. Kimmel, and Donald E. Kieso. Financial Accounting IFRSEdition, 3rd ed. USA: Wiley, 2015. 